\title{
Modelling of Roller-raceway Contacts in the Slewing Bearing Taking into Account Asymmetrical Load Transfer Through a Roller
}

\author{
Marek Krynke \\ Czestochowa University of Technology. ul. J.H. Dabrowskiego 69, 42-201 Czestochowa. Poland. E-mail: ma- \\ rek.krynke@wz.pcz.pl
}

\begin{abstract}
During the operation, a slewing bearing is always subjected to a set of combined loads. It is the source of deformation of ball-raceway contacts, rings, and even supporting structures. In practice, deformation of rings and supporting structures is often neglected for simplification, that is, they are supposed to be ideally stiff. To take elasticity of rings and supporting (fixed) structures into consideration, the finite-element method (FEM) is applied. In slewing bearings, a great number of contact pairs are present on the contact surfaces between the rolling ele-ments and raceways of the bearing. In order to improve the computational efficiency of load distribution of large roller slewing bearing, a computa-tional model using one-dimensional finite elements (nonlinear elements) is presented in this paper. In this model, each roller is simulated by a group of nonlinear elements truss, which has the same load-deformation perfor-mance with solid roller-raceway contacts. The results show that a group of parallel springs can be used to replace the solid roller and simulate the line contact performance between the roller and raceway. Obtained results are presented as graphs.
\end{abstract}

Keywords: Slewing bearing, Load distribution, Contact zone, FEM

\section{Intruduction}

The Rotation mechanisms of lifting devices are usually constructed with the use of slewing roller bearings. These are the sub-assemblies of machines that carry the entire load resulting from the operation of the machine. Due to the high load capacity, relatively compact construction and small dimensions, they are used not only in classic machinery and equipment such as excavators, all types of cranes and other construction machinery, military vehicles but are also widely used in wind power plants, rail vehicles and many other devices $[1,2]$.

The bearings are usually subjected to the combined action of radial load $H$, axial load $Q$, and tilting moment load $M$ during the operation of the host machine. The slewing bearing load capacity usually limits the maximum external loads of the designed machine and the correct estimation of it is an important part of the working machine calculation. Slewing bearings are usually selected for extreme loads, so that their work is at the limit of endurance. This requires careful and precise calculations of their performance parameters, of which still the most important is the static load capacity $[3,4]$.

The operational fault of a slewing bearing caused by failure during application will not only bring huge economic losses for the maintenance downtime of the host machine but also may even cause major personal safety accident. During the design stage of slewing bearings, full strength check calculation is an important premise to ensure their safe use $[5,6]$.

Generally speaking, static calculation analysis can be divided into three categories: empirical formulas, analytical methods, and numerical methods. Empirical formulas are convenient, but their computational results are not accurate and the range of application is limited. Analytical methods are only used for slewing bearings under the axial force and the overturning moment, and the calculation is based on a number of assumptions. The result has relatively high accuracy. Currently, the numerical method based on the finite element is the main method in the life and strength calculations of slewing bearing, which always provides high accuracy [7,8].

Slewing bearings usually have large size and hundreds of rolling elements, and contact analysis between the rolling elements and raceways requires many nonlinear contact operations in the entity FEM model of a slewing bearing. Large-scale calculation has high demands on computer resources and will bring huge difficulties in calculation convergence. That's why in FEM models the rolling elements are replaced by one-dimensional finite elements (linear elements) to simplify the computation procedure and to obtain an optimal time for computations $[9,10]$.

\section{Replacement rolling elements in the slewing bearings}

Building of FEM models of the slewing bearings, due to their complex construction, offers many difficulties. An adequate modelling the rolling elements is one of them. FEM model of the contact zone of one rolling element with raceway at sufficient accuracy contain from several to tens of thousand degrees of freedom [11]. Due to large number of these elements (tens or more), construction of a full model of the bearing, taking into account the shape of rolling elements and the modelling the contact problem for each of them, is practically impossible. The difference in scale of systems rolling element - raceway and support-construction makes it difficult to obtain exact accuracy of computations and to obtain convergence of numerical solution due to too high differences in rigidities between individual finite elements [12]. It should be noted that computations considering geometrical and physical nonlinearity are required to be carried out. So, to simplify computation procedures and to obtain optimal time of computations, the rolling elements in 
FEM models have been replaced by one-dimensional finite elements (linear elements). The most often applied finite elements replacing rolling elements in computational models of slewing bearings are:

- the truss elements with adequate unilateral nonlinear material characteristic stress - strain [11],

- $\quad$ special elements (super-elements), mainly for ball bearings, on the basis of super-element proposed by T. Smolnicki in [13].

Replacement elements in the form of the truss elements are applied first of all to roller bearings where rollers are replaced by singular truss elements with the length equal to the diameter of roller. The system of two or more truss elements can be also used to substitute rollers what makes it possible to model asymmetrical transfer of the load by the roller (Fig. 1). This kind of replacement elements can be applied to computational models of ball bearings with constant contact angle equals $90^{\circ}$.

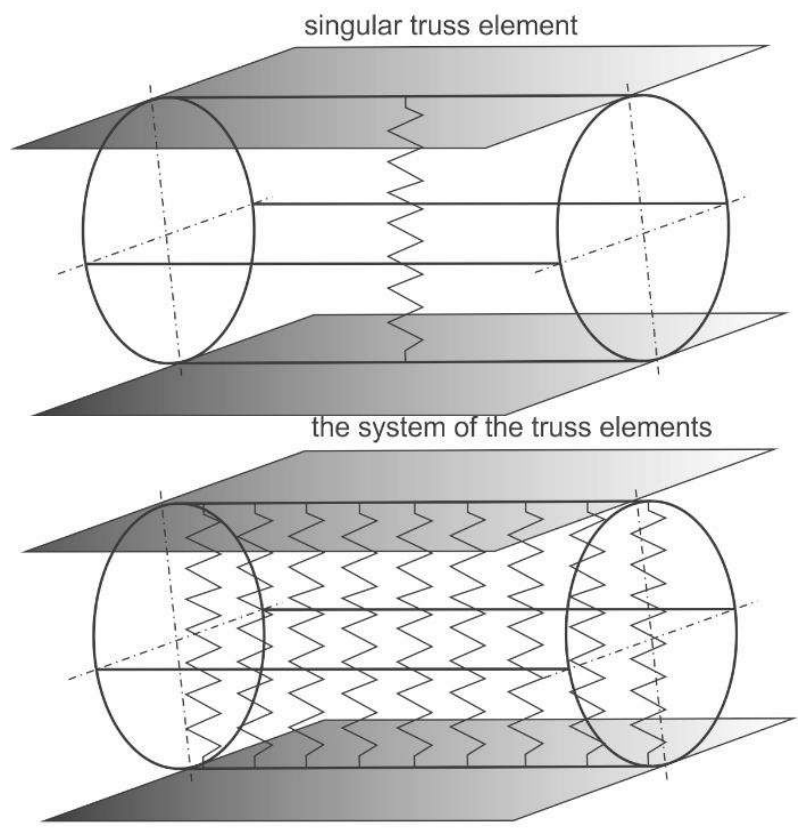

Fig. 1 Replacement truss elements for rollers: singular truss element, the system of the truss elements

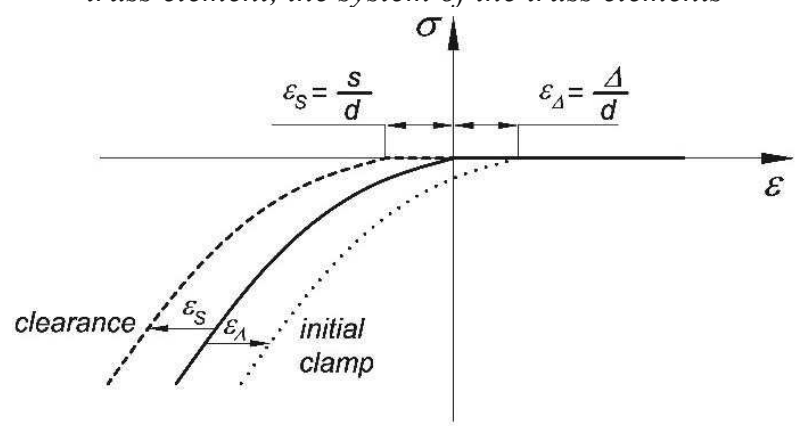

Fig. 2 Characteristic of stress - strain of the truss element replacing rollers in FEM models of the bearings

The truss element is of exactly definite length and cross-section as well as appropriately determined material characteristic $\sigma(\varepsilon)$. This element is performing a role of non-linear spring [11]. An assumed axial clearance $\mathrm{s}$ of the bearing or initial clamp $\Delta$ in FEM models can be directly determined by displacement of material characteristic of the truss element according to direction of strain $\varepsilon$ as shown in Fig. 2 or by using additional contact elements with adjustable gap, e.g. elements of gap type.

\section{The numerical model of the double-row sle- wing rings roller/ball combination bearings}

DoubleThe double-row slewing rings roller/ball combination bearings (Fig. 3) is destined are aimed for applications with small eccentricities at relatively high axial loads, which call for a long service life, even with continuous oscillating motions, and where the structural design requires a large bearing diameter. For this bearing type, the eccentricity:

$$
k=\frac{2 M}{d_{t} \cdot Q}
$$

should not exceed 1.2 under operating loads.

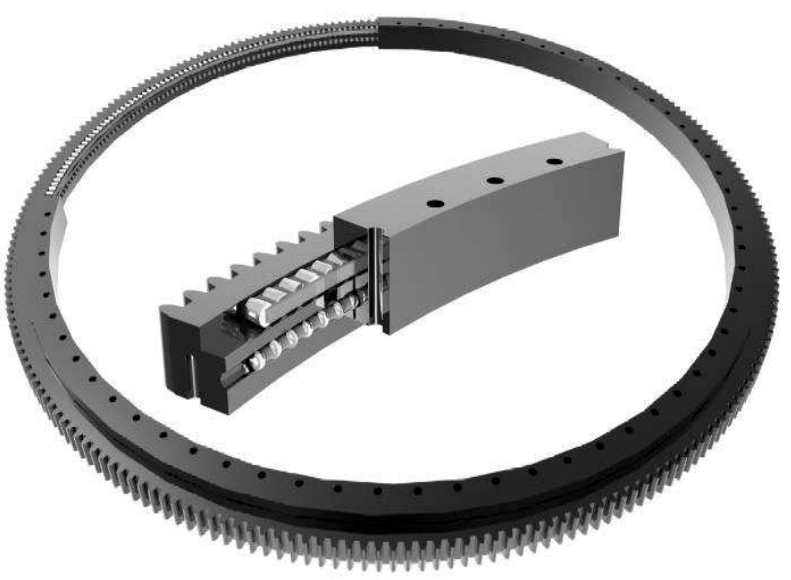

Fig. 3 Double-row slewing rings roller/ball combination bearings

Tab. 1 Parameters of slewing bearings analysed in the study [15]

\begin{tabular}{|c|c|c|c|}
\hline Bearing parameter & 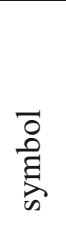 & 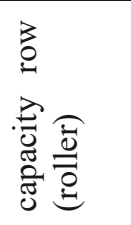 & 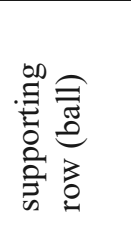 \\
\hline $\begin{array}{l}\text { Rolling diameter of } \\
\text { a calculation row [mm] }\end{array}$ & $d_{t}$ & 3550 & 3506 \\
\hline $\begin{array}{l}\text { Diameter of rolling } \\
\text { elements [mm] }\end{array}$ & $d$ & 32 & 25 \\
\hline $\begin{array}{l}\text { Number of rolling ele- } \\
\text { ments in the calcula- } \\
\text { tion row }\end{array}$ & $z$ & 304 & 304 \\
\hline Roller length [mm] & $l$ & 30 & - \\
\hline Contact coefficient & $k_{p}$ & - & 0.96 \\
\hline Operation angle [deg] & $\alpha_{0}$ & $90^{\circ}$ & $45^{\circ}$ \\
\hline Race hardness & & $54 \mathrm{HRC}$ & $54 \mathrm{HRC}$ \\
\hline
\end{tabular}


The slewing bearing is a complex construction. The numerical model of the bearing is made using FEM. ADINA software was applied to this [14].

Calculations of the load capacity profiles of slewing bearings were made for a double-row slewing rings roller/ball combination bearing with the parameters as presented in Table 1.

Two groups of problems can be distinguished during building the model: bearing modelling in macro scale, it means modelling bearing rings and their mounting and modelling bearing in local scale, it means modelling phenomena in the contact zone of rolling elements and bearing raceways.

The numerical modelling of a bearing in macro scale is reduced to preparation of mesh of bearing ring models, acceptance of shape of mounting elements and acceptance of the method of modelling bearing clamping bolts. Constructional details of elements to which a bearing is mounted are not known at the stage of computations of the catalogue capacity. It was assumed that bearing rings are fastened on the ring-girders.

It is also important simplifications is connected to the modelling method of clamping bolts of a bearing. It was assumed that the bolts are modelled using beam elements. This allows to introduce an initial tension in bolts. Elements of BOLT type are applied to achieve this in ADINA software [14].

8-nod elements of 3D-SOLID type were applied to discretization of bearing rings. The following simplifications of the shape of bearing rings were introduced to model bearing rings: toothing of bearing rings was omitted, small constructional details, such as grooves for gaskets, grease holes, etc., were omitted, holes for clamping bolts were omitted.

The method of modelling bearing rings and clamping bolts is shown in Fig. 2 on the example of the mesh of model of a double-row roller/ball combination slewing bearing. Segmentation of rings over the circuit is regular and mesh density is conditioned by arrangement pitch of the rolling elements.

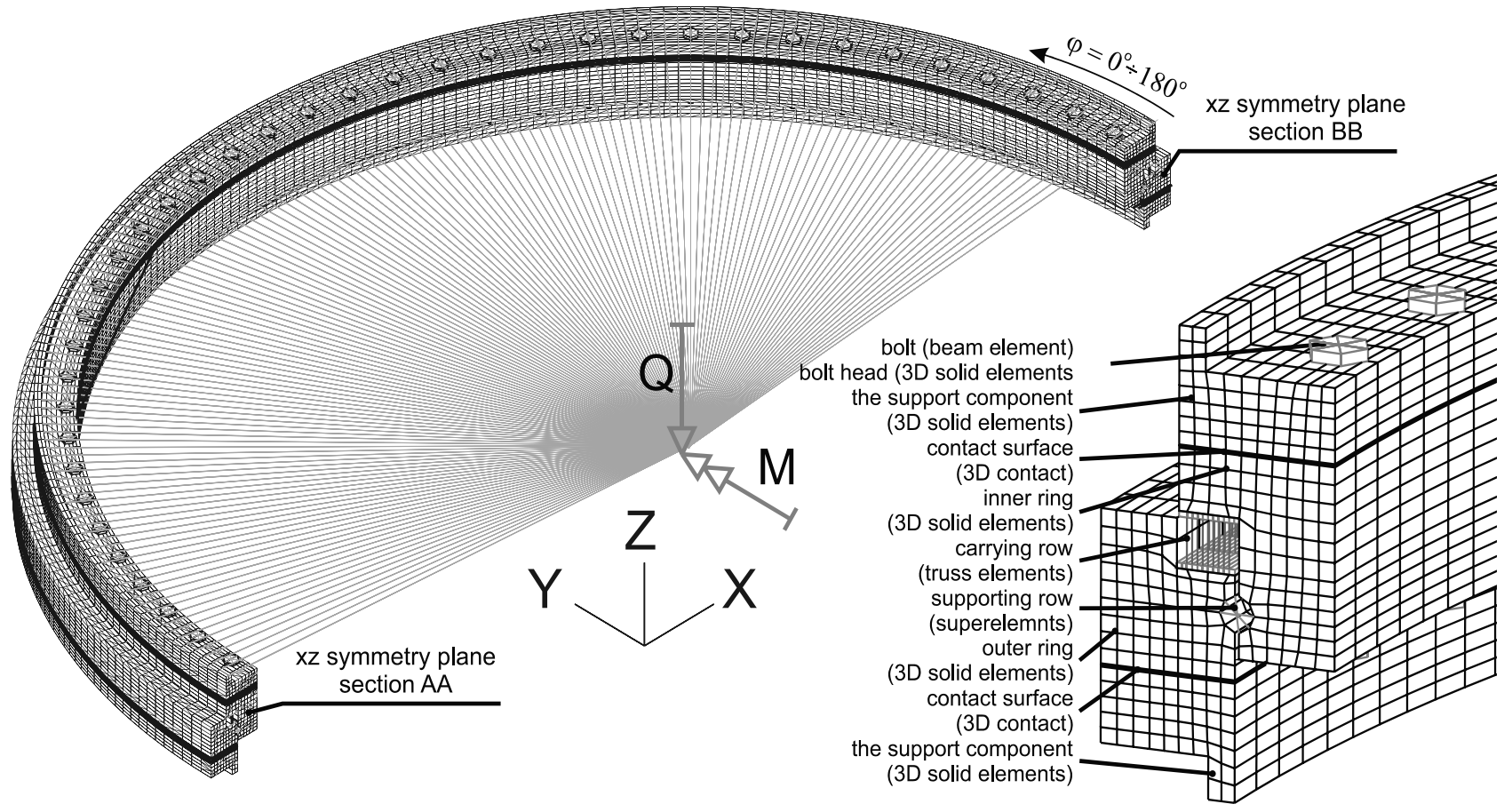

Fig. 4 Mesh of the numerical model of double-row roller/ball combination slewing bearing (with sectional rings) and boundary condition

Due to symmetry of the problem (tilting moment is acting in the plane determined by axial and radial load) only half of the ring structures were taken for computation, as in Fig. 2. In the plane of division of rings, the adequate constraints resulting from symmetry were applied. One of girders of a bearing mounting is fastened by its bottom plane. It is called the support girder. The load is imposed on the second girder - called the load girder.

\section{Results analysis}

Figure 5 presents the charts that illustrate the static load capacity profile for the slewing bearings a roller/ball combination slewing rings. The chart also show the scopes of specific cases of bearings operation of bearings for nominal states (without play). In the AB range, the load capacity is determined by the load capacity of a row, which is limited by the permissible force of a roller. The $\mathrm{AB}$ range is the place where only the rolling elements of the load-carrying row are operating, while the rolling parts in the supporting row do not take part in transferring the external load.

Figure 6 presents the chart that illustrate distribution of internal load in the bearing for $k=0.6$ (B point - Fig. $5)$.

The distribution also takes into account the load distribution along the roller. In contrast, Figure 7 shows the percentage change in the load of the roller over its length depending on the position it take in the bearing. 


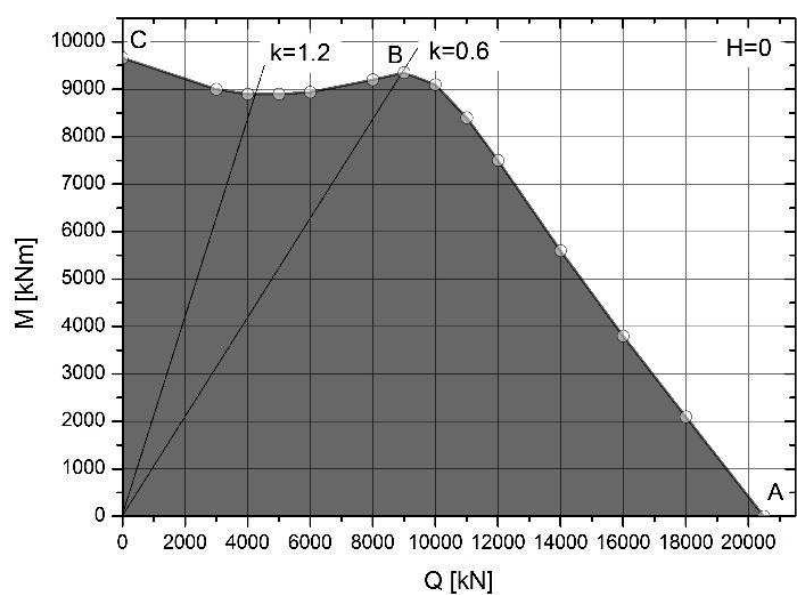

Fig. 5 Characteristic of a double-row roller/ball combination slewing bearing with parameters from Table 1

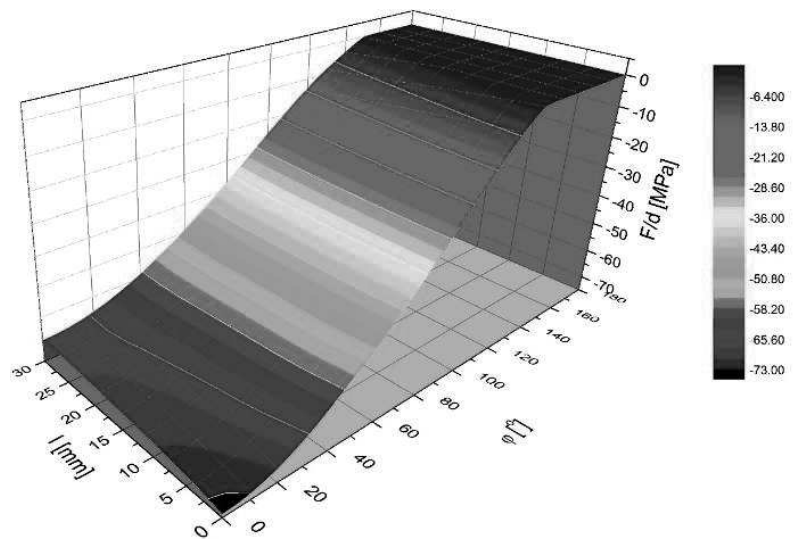

Fig. 6 Distributions of the internal load in a double-row roller/ball combination slewing bearing for individual points B marked in Fig. 5

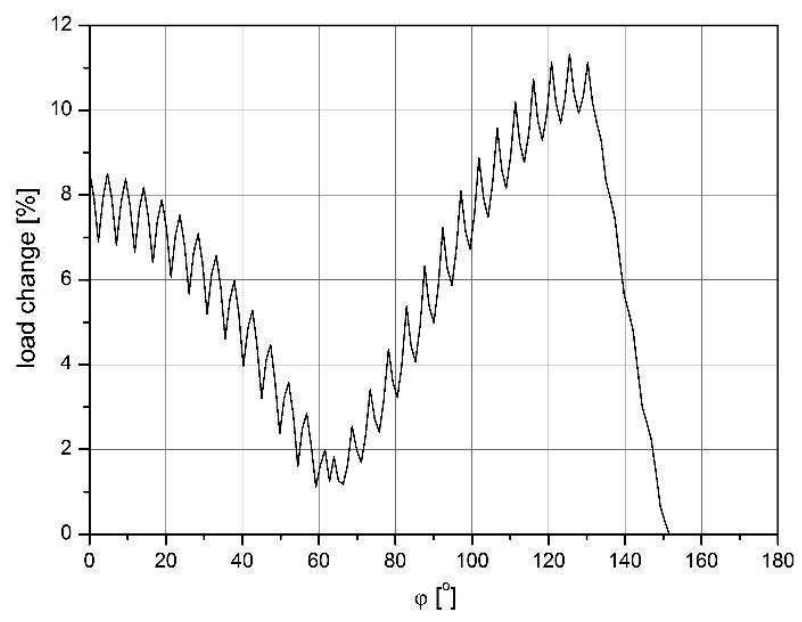

Fig. 7 Unevenness of the load along the length of the roller depending on the position it take in the bearing

Figure 7 shows how the value of the roller load changes over its length for selected roller positions along the circumference of the bearing race. This distribution also applies to the case when the bearing works in point B of its capacity characteristic.

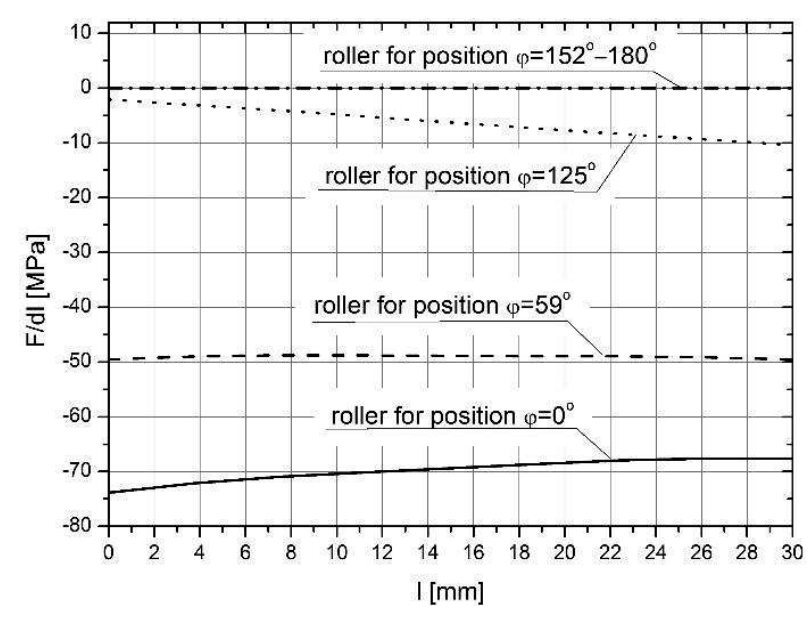

Fig. 8 Load distribution along the roller contact line for its selected positions along the circumference of the bearing race

The results presented show that in cylindrical roller bearings, there is an uneven load on the roller along its length. For a bearing loaded with a high tilting moment, the forces occurring at the ends of the roller may vary by up to several percent.

\section{Conclusion}

This paper proposes a computational model of a double-row roller/ball combination slewing bearing in which the rolling parts were replaced by one-dimensional nonlinear replacement elements (nonlinear element truss). The method of modelling the rolling elements, which are replaced by special elements (super-elements), is the key stage in the presented computational methodology. Both the structure of the super-element and its substitute characteristics can have a profound influence on the obtained results of computations.

When subjected to external loads, the inner and outer rings will deform, so that the deformation of roller along the contact line may differ. A group of nonlinear element truss can simulate different deformation along the contact line. To obtain an adequate characteristic of the bearing capacity, one must take into account both phenomena proceeding occurring in the contact zone of the rolling elements and raceways, and the influence of the method of the rolling element modelling in the FEM numerical model of the a bearing.

The results show that a group of parallel nonlinear element truss can be used to replace the solid roller and simulate the line contact performance between the roller and raceway, but a single equivalent nonlinear element truss is not recommended because of the low computational accuracy.

\section{References}

[1] KRYNKE, M., MIELCZAREK, K. (2016). Analysis of causes and effects errors in calculation of rolling slewing bearings capacity. Production Engineering Archives, Vol. 12, No. 3, pp. 38-41. 
[2] JAKUBOVIČOVÁ, L., SÁGA, M., VAŠKO, M. (2013). VaškoImpact analysis of mutual rotation of roller bearing rings on the process of contact stresses in rolling elements. Manufacturing Technology, Vol. 13, No. 1, pp. 50-54.

[3] ULEWICZ, R., MAZUR, M. (2013). Fatigue testing structural steel as a factor of safety of technical facilities maintenance. Production Engineering Archives, Vol. 1, No. 1, pp. 32-34.

[4] KRYNKE, M., SELEJDAK, J., BORKOWSKI, S. (2012). Diagnosis and Damage of Bearings. Manufacturing Technology, Vol. 12, No. 13, pp. 140144.

[5] KNOP, K., MIELCZAREK, K. (2016). Significance of visual control types in automotive industry. Czasopismo Techniczne. Mechanika, Vol. 113, No. 3-M, pp. 67-72.

[6] ULEWICZ, R. (2014). Practical application of quality tools in the cast iron foundry. Manufacturing Technology, Vol. 14, No. 1, pp. 104-111.

[7] SPIEWAK, S. (2016). Methodology for calculating the complete static carrying capacity of twin slewing bearing. Mechanism and Machine Theory, Vol. 101, pp. 181-194.

[8] KRYNKE, M., ULEWICZ, R. (2019). Analysis of the influence of slewing bearing mounting on their static load capacity. Transportation Research Procedia, Vol. 40, pp. 745-750.
[9] WANG, H., HE, P., PANG, B., GAO, X. (2017). A new computational model of large three-row roller slewing bearings using nonlinear springs. Journal of Mechanical Engineering Science, Vol. 231, No. 20, pp. 3831-3839.

[10] KRYNKE, M., MIELCZAREK, K. (2019). Damage Risk of the Raceway Edge Arise in FourPoint Slewing Bearing. System Safety: Human Technical Facility - Environment, Vol. 1, No. 1, pp. 632-638.

[11] KANIA, L. (2006). Modelling of rollers in slewing bearing calculations with the use of finite elements. Mechanism and Machine Theory, Vol. 41, No. 11, pp. 1359-1376.

[12] KRYNKE, M., KANIA, L., MAZANEK, E. (2012). Modelling the contact between the rolling elements and the raceways of bulky slewing bearings. Key Engineering Materials, Vol. 490, pp. 166-178.

[13] SMOLNICKI, T., RUSINSKI, E. (2007). Superelement-based modeling of load distribution in large-size slewing bearings. Journal of Mechanical Design, Vol. 129, No 4, pp. 459-463.

[14] ADINA. (2012), Theory and Modeling Guide. ADINA Solids \& Structures, Vol. 1., Inc., Watertown.

[15] ROTHER ERDE. Slewing Bering. Katalog, 2016. 